\title{
LOCAL AN AESTHESIA AS A GUIDE IN THE DIAGNOSIS OF LESIONS OF THE UPPER PORTION OF THE SPINAL CORD.
}

\author{
BY M. ALLEN STARR, M.D., PH.D. \\ Professor of Diseases of the Mind and Nervous System, College of Physicians \\ and Sturgeons, New York.
}

THe importance of the careful analysis of special symptoms and of their relation to localised lesions in the nervous system can hardly be exaggerated. There is perhaps no better proof of this statement to be cited than the exact results which have been reached by the study of paralysis and anæsthesia following transverse lesions in the spinal cord. It has been possible to determine the various levels or segments of the cord which are in functional relation with certain muscles and regions of the skin. This has been most exactly worked out for the lower half of the body and its relation to the lower portion of the spinal cord by the independent researches of Thorburn ${ }^{1}$ and myself, ${ }^{2}$ and recently by Head. ${ }^{3}$

'The "Surgery of the Spinel Cord," 1889 ; also BraIs, 1893, p. 373.

Thorburn's criticism that my diagram shows no skin areas connected with the fourth lumbar and second sacral nerves is not quite just, as the following quotation from my article shows:-

"The fourth some is of a similar shape to the third, but more extensive, a greater surface on the back of the thighs being involved, and the anesthesia ertends in a band almost as low as the popliteal space. This area has been established clinically in several cases: there is as yet no sutopsy to determine its lesion; but since the smaller zone is due to lesion at the third secral gegment, and the next larger zone is due to lesion in the fifth lumber segment, it is allowable to conclude that this region corresponds with the second and first secral segments. In thus outlining four zones of the skin and assigning them to various segments of the sacral portion of the spinal cord, it is not my intention to lay down artificial boundaries or to affirm that all cases will exactly coincide. I only wish to show that as the cord is invaded by disease from below upward, the area of the skin which becomes anesthetic increases in extent, and that the shape of the ares is characteristic; so that from the study of the area the extent of the lesion can be determined. The sixth sone 
As a further contribution to this subject I propose in the present article to consider the anæsthesia produced by lesions of the cervical segments of the cord. This will be less difficult since cases are not wanting both in the recent literature and in my own experience to aid in this study.

A few remarks regarding the anatomy of the cervical segments of the cord and the relation of these segments to the cervical vertebræ may not be out of place. It is to be remembered that there is no natural boundary between adjacent segments of the human cord. The nerve roots issue from the cervical cord in a continuons series, and it is only by following out individual nerve roots to the various points of exit, through the dura mater, that it is possible to trace any one particular root into the cervical nerve to which it belongs. If, on the other hand, any nerve be traced into the cord, it will be found to sub-divide, some portions passing directly into the gray matter, others turning downward and others ascending in the cord, so that any one root really reaches several levels of the cord.

It cannot therefore be affirmed that individual segments of the cord are in any special or direct relation with single cervical nerves, and therefore the symptomatology of spinal cord lesions in the cervical region at different levels will be different from the symptomatology of lesions of the individual cervical nerves, or even of lesions of the nerve roots.

of anesthesia is produced by a lesion of the third lumbar segment. When the third lumbar segment is diseased, the entire back of the thighs and legs is anæsthetic, and the front of thighs is also anæsthetic, except over a funnelshaped zone which extends from above downward, the narrow tube of the funnel reaching along the shin even to the foot. This zone will probably be separated later into two separate parts corresponding to lesions of the fourth and third lumbar segments. There is not as yet a sufficient number of cases to warrant such a distinction. The exact limits of anæsthesia on the faet are still uncertain, and no more exact statement than that given is warranted."

It eeemed to me better to abide closely by actual facts than to assert con. clusions without the pathological basis of exact spinal lesions. I do not think any deflnite conclusions can be deduced from cases of pressure on the cauda equina. While I think it quite probable that Head and Thorburn are correct in essigning the sole and outer side of the foot to the first sacral segment, I know of no case of spinal cord lesion with autopsy to establish this fact.

American Jourmal of Modical Sciences, 1892, and Amorican Journal of Neurology, 1884.

${ }^{3}$ Braw, 1899, p. 44. 
In discussing lesions of the cervical enlargement of the cord, authors bave usually been contented to describe the symptoms produced by destruction of the lower, middle and apper thirds of the enlargement, and this is perhaps sufficiently accurate for all parposes of diagnosis. Nevertheless, after the study of the cases here collected I shall attempt to assign to each segment its special function, although it is admitted at the outset, that scientific precision rather than practical use will be the chief result.

The relation of the cervical segments of the cord to the spines and bodies of the vertebre is by no means a constant one. It will be remembered that Gowers in 1884 published a diagram to demonstrate these relations which has been accepted ever since that time. Gowers says : " "The first three cervical spines are opposite the origin of the third, fourth and fifth cervical nerves. The sixth and seventh pairs arise opposite the intervals between the fourth and fifth, and the fifth and sixth, cervical spines respectively. The sixth cervical spine corresponds to the origin of the eighth cervical nerve, and the seventh cervical spine to the first dorsel nerve. Thus the cervical eulargement of the cord which ends at the origin of the first dorsal nerve corresponds nearly to the bodies and spines of the cervical vertebra."

While this summary is undoubtedly very nearly correct it must be admitted that it does not hold for all cases. In 1891, Kraus called attention ${ }^{2}$ to the fact that fractures of the sixth and seventh cervical vertebræ crushing the cord often produce very different symptoms in different individuals, the extent of the paralysis being by no means uniform, although the site of the fracture is the same. This fact was confirmed in 1892 by the series of cases published by Church and Eisendrath. ${ }^{3}$ The facts presented by these authors can only be explained upon the supposition that in different individuals the relation of the segments to the vertebro differs.

Quain in the last edition of his "Anatomy" admits this fact. Quain states that the lower limit of the cervical enlargement

1 "Diseases of the Spinal Cord," 1884, p. 6.

"Zoitschrift ful Klin. Med., rviii.

\& Amer. Jour. Med. Scionces, A pril, 1892.

VOL. XVII. 
lies opposite the body of the first or second thoracic vertebra. But inasmuch as the thickness of this body is at least an inch, it is evident that this implies a decided variation in the relation of individual segments of the cord to the vertebræ. This variation is also brought out by a diagram of Reid ${ }^{1}$ shown in fig. 1. The position of attachment of the nerve roots to the spinal cord in six adult subjects and the relation of these to the spines of the vertebro are shown in the diagram. It is evident from its study that no exact conclusion can be drawn as to which segment of the cord is destroyed in a fracture of one vertebra. The possible

\section{NERVE ROOTS. SPINOUS PROCESSES}

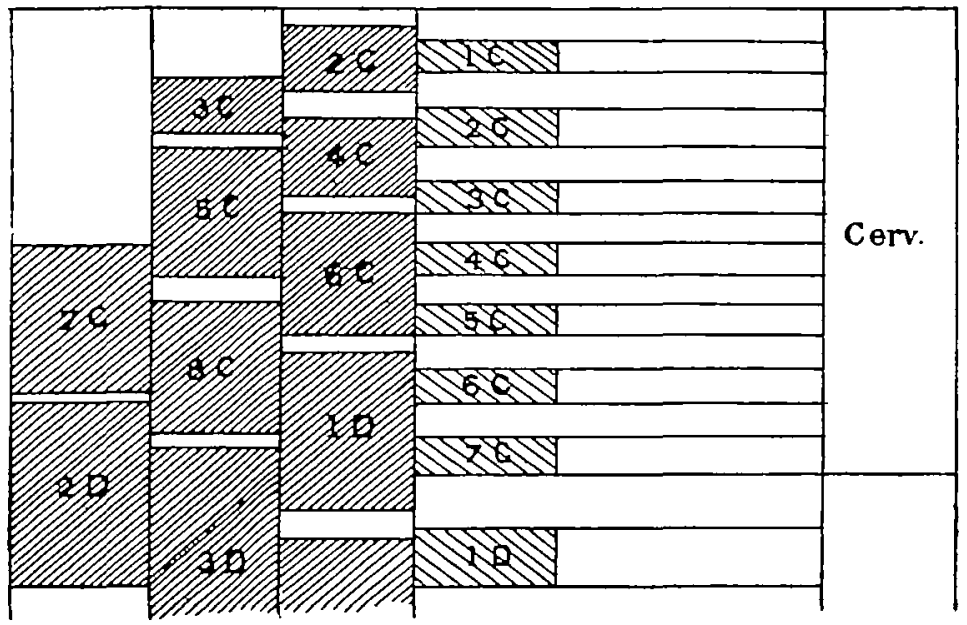

F'IG. 1.

Chart showing the limits of the rariations in the topographical relation between the superficial origins of the nerve roots from the spinal cord and the spinous processes of the vertebrw.-Reid."

result, for example, of a fracture of the serenth cervical vertebra would be a destruction of either the eighth cervical segment or the third dorsal segment or segments between these in different cases. It is evident, therefore, that while Gowers' statement may be taken as representing the average

' Jour. of Anah and Phys., rriii., 1889.

'Jour. of Anat. and Phys., 1889, vol. xriii., p. 341. 
condition, there are consideruble variations in the relation between the cord and the spine.

There is another fact which must be stated as a necessary preliminary to the study of anæsthesia due to spinal lesions, the fact which has recently been brought out by the investigations of Sherrington. ${ }^{1}$

Sherrington found, in an attempt to determine the area of the body functionally related to the various posterior nerve roots in the monkey, that division of one root alone was not attended by any anæsthesia, and that to determine the area of skin supplied by a single dorsal nerve it was necessary to divide at least three dorsal nerve roots. ${ }^{2}$

The conclusion to be drawn from Sherrington's re. searches, as shown in his diagram (fig. 2), is that every part

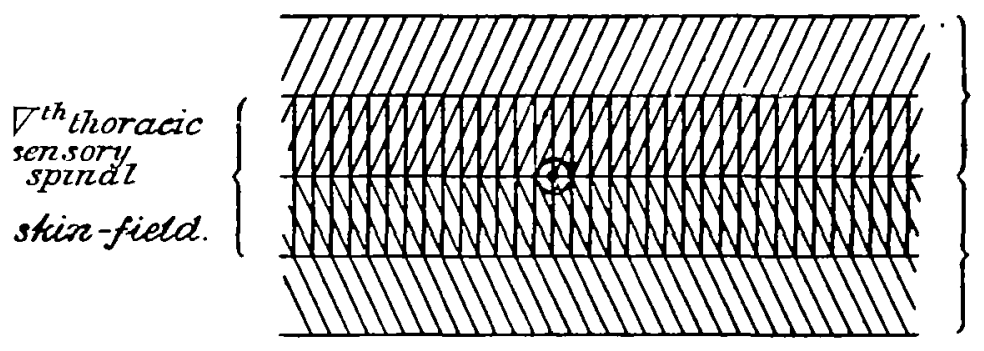

III thoracic.

Fig. 2.

of the skin is supplied with sensation by three sensory nerve roots, whose peripheral branches overlap one another or anastomose. In order to deprive the area of skin of sensibility, all three nerve roots must be cut. This fact gives the rational explanation to the correlated fact which has been observed by clinical investigators, and to which attention was called especially by Horsley and Gowers in $1889 ;^{3}$ namely, that in a transverse lesion of the spinal cord, the

I “ Experiments in eramination of the Peripheral Distribution of the Fibres of the Posterior Roots of some Spinsl Nerves."-Philosoph. Transactions of the Royal Saciety of London, vol. clmxv., B. p. 641. Charles S. Sherrington.

'I have conflrmed this observation in man; for in a case of spinal injury recently operated upon by Dr. McCosh for me, one pair of dorsal nerves was divided, but no anesthesia was produced.

"Medico-Chirurgical Transactions, vol. lnxii., p. 21 : " Report of a Cose of Tumour of the Spinal Cord." 
band of anæsthesia about the body was uniformly at a level from two to four inches lower than the level of the lesion in the cord. If, for example, as in my first case, the level of anæsthesia is about the body at the level of the nipples, that is, corresponding to the fifth dorsal nerve, the lesion in the cord cannot be lower than the fourth dorsal nerve or fourth dorsal segment. For were it at the fifth dorsal segment, the fourth dorsal nerve being still intact would supply with sensibility the skin in the fifth dorsal area. This fact is of practical importance in determining the position of a lesion in the cord, such as a tumour, and justifies the dictum of Horsley, that in removing tumours from the cord the tumour is to be sought from two to four inches above the level indicated by the line of anæsthesia. I can confirm this from my own observation in two cases of spinal cord tamours recently successfully removed, and which will be reported elsewhere.

This fact of collateral supply of skin by adjacent nerves will also explain the clinical fact that the distribution of anæsthesia upon the arms in lesions of the cervical cord is not always uniform.

With these preliminary observations, I will now proceed to relate a number of cases from my own experience and from reliable observers, which demonstrate the various symptoms produced by lesions at various levels of the apper dorsal and cervical segments.

Case I.-Transverse lesion at the fourth dorsal segment of the cord. Unusual symptoms. Remarks.

H. D., aged 46, had always been in good health until his present illness, though he had a chancre with slight secondary symptoms of syphilis in 1882 . On December 4, 1884, without any apparent cause he began to suffer from pain in his back, and the next day he became suddenly paralysed in legs and body, lost sensation below his navel and lost control of his bladder and rectum. The condition of total paraplegia had remained up to the time I first saw him, in consultation with Dr. L. A. Sayre on October 24, 1888; and remains at present (1894). His condition on October 24, 1888, was as follows :- 
He lay upon a smooth, hard bed, totally naked, and apparently in considerable pain, and was turned every ten minutes from one side to the other by his attendants, by being lifted on a sheet, as this was the least painful method. The pain caused by the dorsal position was too great to be endured. His pain was referred to the spine at the fifth dorsal vertebra. There was no deformity there, bat he was extremely tender to touch, and to a hot sponge over an area three inches wide the centre of which was at the fifth dorsal spine. He was accurate in all his statements.

Sensation.-There was a condition of absolute anæsthesia to touch, temperature, pain, and muscular sense, below the level of a line extending round the body at the level of the fifth dorsal spine. This line did not follow the course of the fifth intercostal space but in front was just opposite to the level behind, being
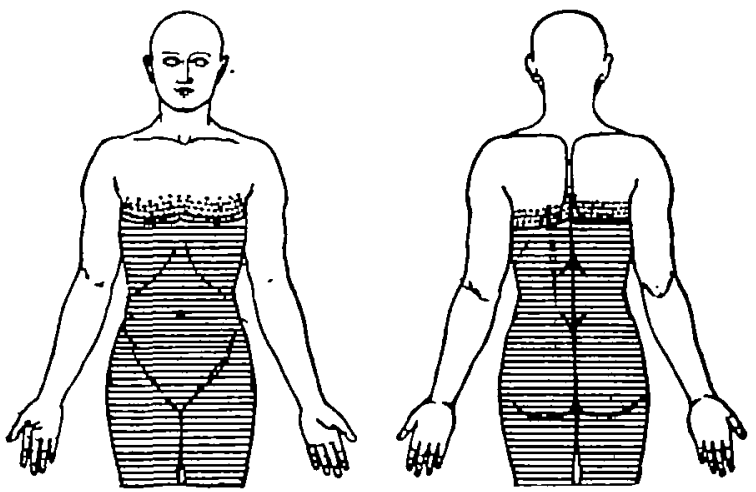

FIG. 3.

Case I.-Starr. Anmsthesia in lesion at fourth dorsal segment.

about an inch below the nipples. It was not an absolutely straight line, however, appearing to dip down a little behind on the left side. (Fig. 3.) Above this anæsthetic line there was a zone of very intense hyperæsthesia of three inches in width, its upper limit fading off into that of normal sensation. The hyperæathesia was so extreme that any touch was painful, and hence he would not allow even the bed clothes to cover his body, and he always lay naked in a very hot room. The sensation of all parts above the hyperæsthetic area was perfect. Whenever he was touched at any spot in the anasthetic area he felt pain in the back at the fifth dorsal vertebra. This statement was repeatedly confirmed. A touch or prick on the foot or abdomen was felt in the back but not at the point touched. 
Motion was absolutely lost in all muscles of back, body, and legs below the fifth dorsal vertebra. It was perfect in the arms. The muscles were somewhat atrophied uniformly, from disuse. They were all relaxed, not at all rigid or contractured, but were abnormally sensitive to percussion and contracted on any strong sensory stimalus like that of a sharp prick on the skin over them. Their reaction to electrical stimulus both faradic and galvanic was normal, and even in the seventh intercostal space reaction was good. His sensitiveness prevented electrical tests of the sixth and fifth and fourth intercostal muscles. His feet were dropped, but not held rigid by contracture.

Reflexes.-Epigastric reflex lost. Gluteal, cremasteric and plantar reflexes normal. Abdominal and patella reflexes in. creased, no ankle clonus. His bladder empties itself spontaneously as soon as about three ounces of urine have collected, but there is no dribbling. For two weeks after the onset there was retention and a catheter was used, but since then active incontinence has been present. His rectum has to be evacuated by digital manipulation.

Vasomotor Condition.-If he lies more than fifteen minutes on any spot it becomes red, and will within a few hours become blue and go on to a bedsore. He has had numerous bedsores, one deep one over the sacrum, which had been healed with difficulty, and scars remain. The application of heat-as by hot bottles-or of electricity, or the mere scratch of a finger nail is soon followed by a broad zone of redness. There is always more or less redness over the bony prominences. It is to avoid bedsores that he is turned every ten minutes day and night. The growth of hair and of the nails was in no way abnormal.

Remarks.-The diagnosis of spinal hæmorrhage or of hæmorrhagic myelitis seemed quite evident in this case, and its level at the fourth dorsal segment of the cord was indicated by the level of the anæsthesia.

There were certain facts which made the case an interesting one, viz. :

First, the limits of the anæsthesia. This did not follow the line of the fifth intercostal nerve and thus describe a curve convexity down around the side of the body, but was practically horizontal to the vertical axis. This confirms the observations of Church and Eisendrath (American Jour- 
nal of Medical Sciences, April, 1892), in five cases, and also Head's statement.

Secondly, the patient, though anæsthetic below this line, felt any touch or pain in the anæsthetic region at a spot in

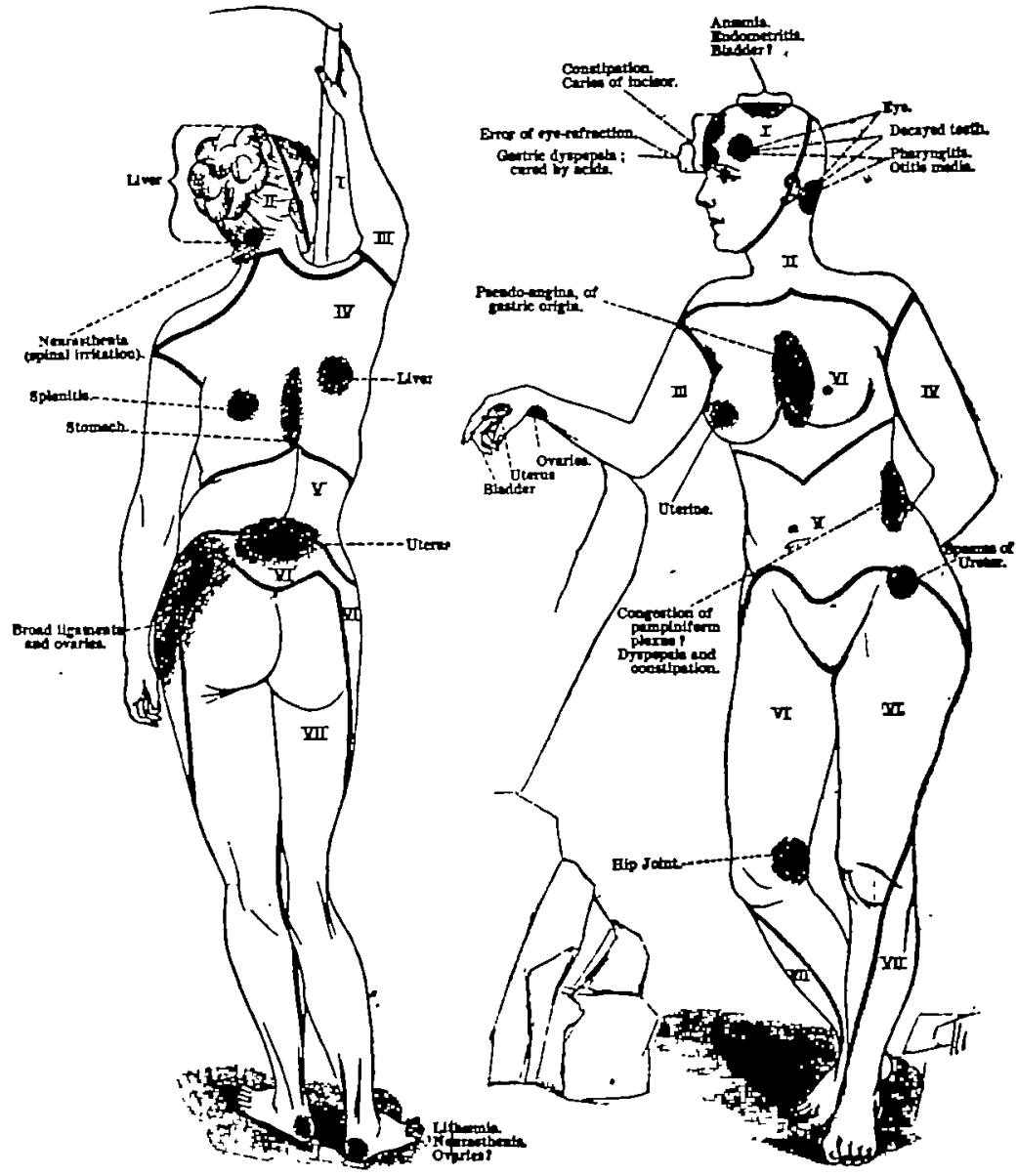

Fig. 4.

Dana. Situation of Referred Pains.

the back at the level of the lesion. I have observed this symptom in several cases of transverse myelitis, though I do not recall any special mention of it in the literature. 
The impression sent inward from the skin evidently travels up the cord to the level of the lesion; there sets up an irritation which is then referred erroneously to the lowest area in which sensation can be felt, viz.: to the hyperæsthetic area just above the lesion. The explanation is the same given by Head in chapter vi. of his article, and long ago offered by Dana in his article on "A Clinical Study of Neuralgias and of the Origin of Reflex or Transferred Pains." New York Medical Journal, July 23 and 30, 1887.) ${ }^{1}$ Such a referred sensation would not be possible in a case of total destruction of the cord, and hence like the loss of knee-jerk, may be of volue in diagnosis.

Thirdly, the absence of rigidity and contraction in the legs after nearly four years of total paraplegia in spite of increased knee-jerks, is in my experience exceptional.

It is common to find a flaccid paralysis after total lesions of the cord which destroy the gray matter in its entire length, and thus remove the tonic influence of the spinal centres. It is also possible to have a flaccid paralysis in the muscles below a transverse lesion of the cord which entirely destroys a single segment, but under these circumstances the absence of knee-jerks (as first shown by Bastian) establishes the diagnosis of a destructive lesion.

In my case the knee-jerks were not lost, and the condition of sensibility just mentioned, proved that a total destruction of the cord, or a complete transverse lesion had not occurred. I cannot offer any explanation for the facts, but think they should be put on record.

Case II. - Fracture of the seventh cervical vertebra, crushing the first dorsal segment of the cord.

Bruns has recently ${ }^{2}$ published a very careful record of a case of traumatic lesion of the spinal cord by a dislocation of the last cervical upon the first dorsal vertebra, destroying

' It must be remarked that many of Head's statements regarding the reference of visceral pain to surfaces of the body are to be found in this remark. able article of Dana which he has apparentily overlooked, and the figure of which is here reproduced. (Fig. 4.)

'Arch. filr Psych., זxv., 759, 1899. 
the first dorsal and lower part of the eighth cervical segments.

The symptoms observed were as follows: complete flaccid paralysis of the legs, with loss of knee and ankle reflexes and of all skin reflexes; parslysis of the body muscles, paralysis of the small muscles of the hands and of the long flexors of the fingers on both sides, with atrophy and reaction of degeneration. Complete anæsthesia up to the second rib and to the spines of the scapulæ; above this, on the body and on the apper extremities hyperæsthesia and pains, but no anæsthesia. (Fig. 5.) Com-
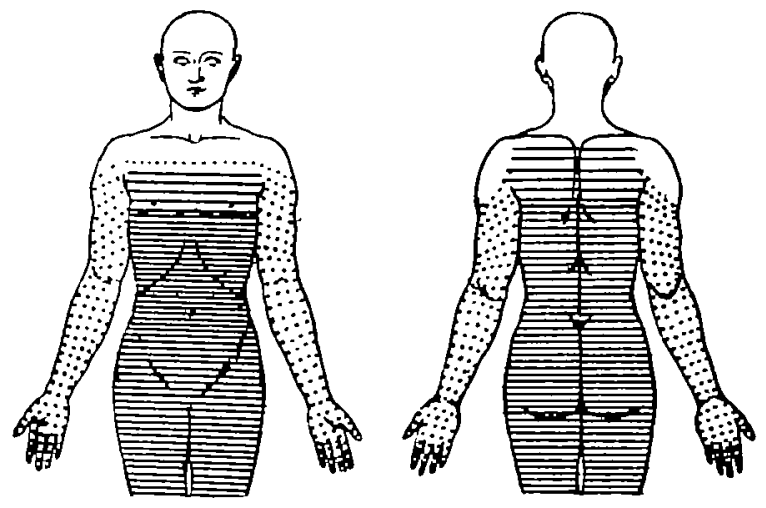

Fig. 5.

Case ПI.-Bruns. Anæsthesia in lesion of first dorsal.

plete paralysis of bladder and rectum, with retention. Purulent cystitis. Priapism. Contraction of papils and narrowing of the palpebral fissures; bedsores; codema of the legs, with trophic disturbances of the skin and joints. This condition changed slightly up to the time of the patient's death, which occurred 104 days after the injury; there being a partial return of sensation as low as the fifth rib on the body, a subsidence of the hyperæsthesia of the arms, a return of pupil and lid condition to normal, and an improvement in the motion of the fingers. 
Remarks. - In view of the fact already established by Reid that the second dorsal segment may lie under the seventh cervical spine; and in view of the fact that recovery of sensation and motion in the arms and hands is inconsistent with a lesion of the eighth cervical segment, I am inclined to suppose that in examining this cord, Bruns has erroneously located the lesion, and that it lay one segment lower than he supposed. This is the only explanation which enables one to bring the facts into harmony with the very namerous cases observed by others.
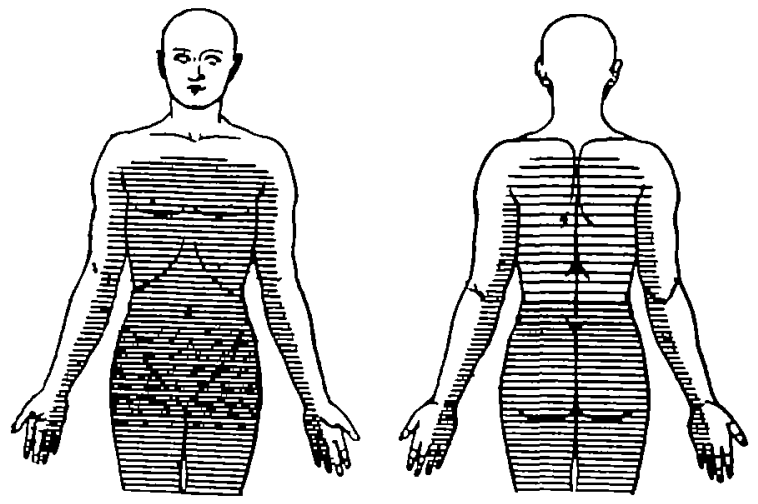

Fig. 6.

Cese III.-Bruns. Anæsthesia in lesion of seventh cervical.

Case III.-Hamorrhagic myelitis after injury to the lower cervical segments. Sensory and motor symptoms.

Bruns reports ${ }^{1}$ another case of injury of the back followed by softening, with hæmorrhage in the lower half of the cervical enlargement. The softening involved the seventh and eighth cervical segments in their entire extent; the sixth segment was a little softened in its central region; the first dorsal segment was normal. The symptoms were total paraplegia with loss of knee-jerks, and paralysis of bladder and rectum. The paralysis involved the hands, there being total paralysis of the fingers, and of the long

' Dout. Med. Woch., 1889, vol. xv., p. 984. 
flexors of the wrist and weakness of the long extensors. Pronation and supination were good and elbow motions unimpaired. The anæsthesia was total up to the level of the umbilicus and partial from there to the level of the second rib. (Fig. 6.) All sensations were lost in the ulnar half of the upper extremities on both dorsal and palmar surfaces, while perfectly preserved on the radial half. The patient died a few days after the injury.

Case IV.-Fracture dislocation of seventh cervical vertebra, crushing the spinal cord at the eighth cervical segment. Motor and sensory symptoms.

Herter reports ${ }^{1}$ a case quite similar to the last one which may be summarised as follows:-A fractare of the seventh

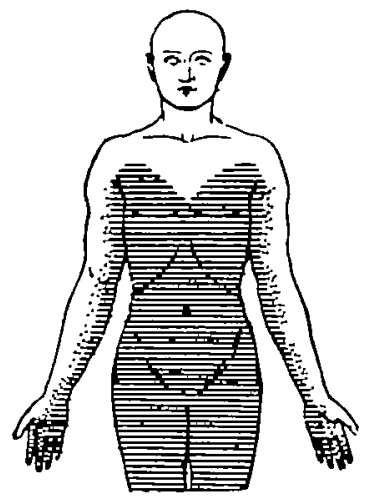

Fra. 7.

Case IV.-Herter. Anæsthesis in lesion of seventh cervical.

cervical vertebra with dislocation forward of the sixtb. The cord was crushed at the eighth cervical segment and softened at the seventh segment, contained numerous hømorrhagic foci which extended into the sixth segment being surrounded by inflammatory cells. The fifth segment was fairly healthy, though showing some inflammation. The paralysis in this case involved the legs and body, and the muscles of the

1 Jour. Nerv. and Mont. Dis., June, 1891. 
hands and forearms, but those of the arms and the supinators and pronators were exempt at the outset. After a few days the pronators were paralysed, and the triceps and biceps became weak. In the paralysed muscles electric reactions were greatly diminished to both currents in five days. Reflexes absent except the cremasteric. The area of anæsthesia, is shown in the diagram. (Fig. 7.) It involved the inner side of both arms and hands, and along its outer limit there was a narrow line of hyperæsthesia.

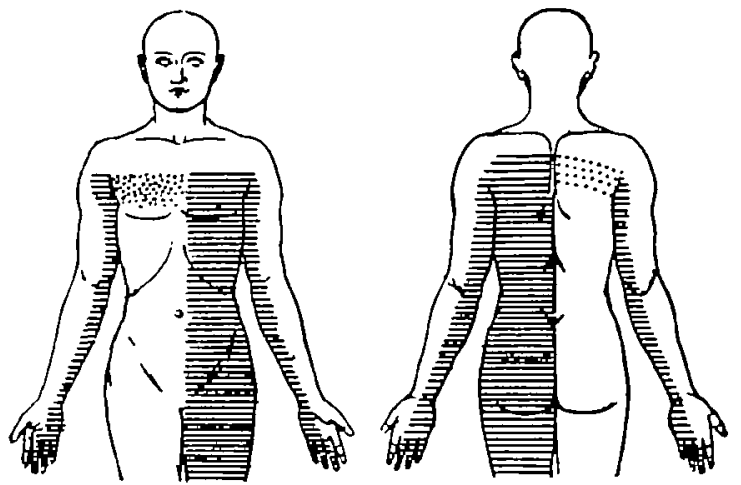

FIG. 8.

Case V.-Williamson. Anesthesia in lesion of seventh cervical.

Case V.-Myelitis of the cervical region with unilateral sensory disturbances. ${ }^{1}$

A girl 13 years old was suddenly seized with paralysis of arms and legs and of the sphincters during the course of typhoid fever, from which she died within a month of the onset of the paralysis. The symptoms observed were paralysis of all four extremities with the exception of the muscles of the upper part of the arm, deltoid, biceps and spinators being exempt. The knee-jerk was lost upon left side. There was no anæsthesia to touch, but sensations of pain and temperature were entirely lost over the left side of the body up to the level of the third rib, and upon the inner sides of the arms as shown in diagram. (Fig. 8.) There was a small

' Williamson, Lancet, January 21, 1899. 
region of hyperalgesia across the right side of the body and back.

The diagnosis was made of a hæmorrhage in the cord, and from the resemblance of the anæsthetic condition to that occurring in syringomyelitis, it was supposed that the gray matter only was affected.

Autopsy showed an acute myelitis without hæmorrhage in the first dorsal and eighth cervical segments of the cord, especially upon the right side.

Case VI.-Fracture dislocation of the sixth vertebra, crushing the eighth cervical segment. Motor and sensory symptoms.

The following interesting case bas been carefully reported by Dr. C. A. Herter. ${ }^{1}$

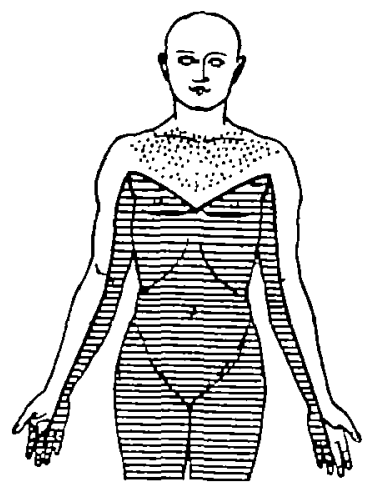

Frg. 9.

Case VI.-Herter. Anmsthesia in lesion of seventh cervical segment.

The patient fell and dislocated the sixth cervical vertebra, which crushed the eighth cervical segment and caused a softening of the seventh cervical segment with hæmorrhage, which extended upward within the central canal to the apper limit of the sixth segment. This condition was found at the autopsy minde two days after the accident.

The symptoms immediately after the accident were com-

' Jour. Nerv. and Ment. Dis., January, 1890. 
plete paralysis and anæsthesia, with loss of all reflexes, excepting the left plantar reflex below the level of the armpits, the hands being noticeably weak but not paralysed. Ten hours after admission the condition of sensation was carefully determined by Dr. Herter, and is shown in fig. 9 . It will be noticed that on the right side the anæsthesia involved the palmar surface of the little, ring, and middle fingers, and of the third phalanx of the index finger; on the dorsal surface it involved the little and ring fingers with the second and third phalanges of the middle finger. On the left hand the little and ring fingers were involved on both surfaces, and the middle finger on its dorsal surface excluding the first phalanx and the index finger at its dorsal top. The anæsthesia of the body was V-shaped in front and passed across the back at the seventh cervical vertebra. There was hyperæsthesia above this level-in front and behind. Deep and superficial reflexes were absent. There was retention of urine.

Within a few hours of the accident the paralysis had extended and eventually involved the muscles of both hands, the flexors and extensors of both wrists and the triceps. There was slight loss of power in the pronators and supinators, and in the biceps and pectoralis major. Both arms were abducted with forearms flexed and supinated nearly in the position described by Thorburn. The rapid extension of the paralysis and death from respiratory failure were ascribed to the extension of the hæmorrhage upward to the sixth segment. The sensory disturbance, which was the same from the first, was ascribed to the lesion at the seventh cervical segment.

It is not necessary to cite further cases, ${ }^{1}$ although a number collected by Thorburn, ${ }^{2}$ and by Chipault ${ }^{3}$ and by White ${ }^{4}$ might be offered as additional proof. It is to be

1 The following cases may be referred to:-Bastian, Med. Chir. Trans., Iondon, 1890, vol. lrxiii., p. 152; Raymond, Revuse Neurologique, 1893, Nos. 5 and 6; George Preston, Med. News, 1898, March 18; Hans Darenberger, Deut. Zeitschr. ful Nerverhoilk, 1893, iv.; Kraus, Zeitschr, fil Klir. Med., Iviii., 849.

" "Surgery of the Spinal Cord."

" "La Chirurgie Médullaire."

" "The Surgery of the Spine." 
noticed that in none of these cases did the lesion destroy the sixth dorsal segment. In none of these cases was the outer surface of the hand and thumb and arm invaded by the anæsthesia. In the following cases the sixth dorsal segment was destroyed.

Case VII.-Dislocation and fracture of sixth cervical vertebra, crushing the cervical cord. Hamorrhage in the cord. Sensory and motor symptoms.

F. H., aged 46, was brought to the Presbyterian Hospital on November 19, 1892, suffering from a fracture of the sixth cervical vertebra, due to a fall. There was tenderness and depression over the sixth and seventh spines and a projection in the pharynx. He was totally paralysed below the waist, and his arms were partially paralyzed. His urine was retained. On the next day, when I examined him, the following condition was present.

Motion.-Patient could not move from the dorsal decubitus and attempts to move his head were too painful and dangerous to be repeated. His arms were abducted, forearms flexed and hands pronated, lying on his chest, in the position described by Thorburn as characteristic of lower cervical lesions. Voluntary acts to produce these positions could be performed. He could not extend his forearms, but could flex and supinate them; all motions in the wrists and fingers were impossible upon the left side and on the right side were very feeble, there being a slight flexion and extension of the long muscles, but none of the intrinsic muscles of the hands.

There was total paralysis of the respiratory thoracic muscles, all respiration being diaphragmatic. He could not move his abdominal muscles. His legs were totally paralyzed and relaxed.

Reflexes.-Epigastric reflex absent. Abdominal and cremasteric reflexes present and normal. Knee-jerks slightly exaggerated. No ankle clonus.

Sensation.-There was total loss of all sensations in front and at the sides up to a line about the body at the 
level of the seventh rib, and very marked diminution of sensations up to the level of the nipples, gradually merging into normal sensation at the level of the third intercostal space. It was not possible to test his sensation on the back, as he could not be moved. (Fig. 10.) The diminution of sensibility to all stimuli was quite well marked upon the arms, its extent being less on the right arm than on the left one. The inner side of both arms and the entire hands were quite anæsthetic, but the outer side of the forearms and arms seemed to have preserved some sensibility above the wrists, this being much more acute on the right arm
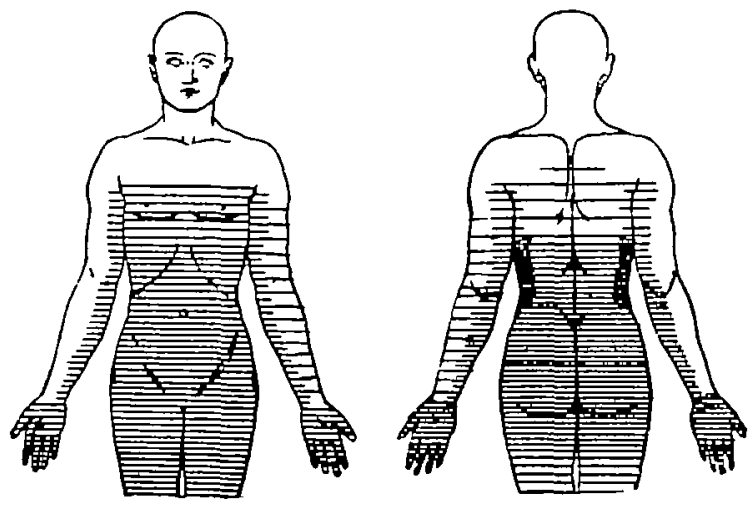

Fig. 10.

Case VII.-Starr. Anæsthesia in lesion of sixth cervical.

and forearm than on the left one. It was not until the deltoid region was reached on the left arm that he felt cotton wool as keenly as upon his face. There did not appear to be any well defined region of hyperæsthesia; yet over the region on the chest above the line of diminished sensibility he seemed to feel pain more acutely than on the face. Touch, pain, and temperature senses were equally impaired.

Bladder and rectum were not under voluntary control. The urine was retained and had to be drawn by catheter. Partial priapism existed. No a.ttempt was made to empty his rectum. 
Prate I.

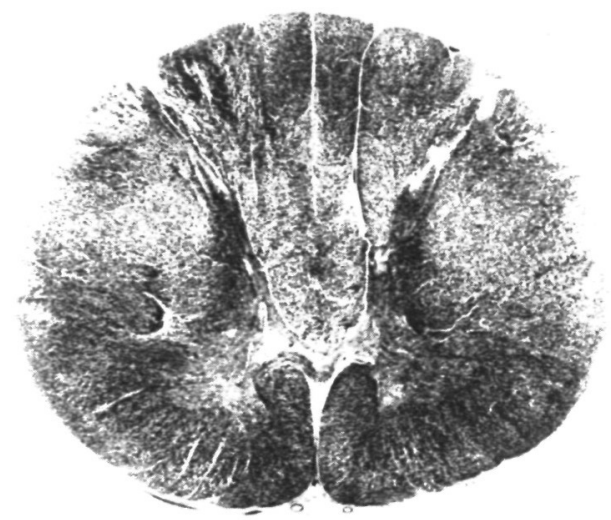

Cerv. V.

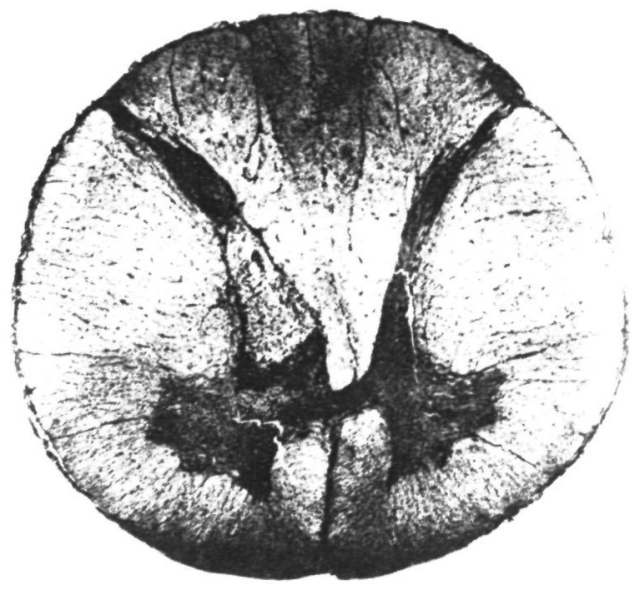

Cerv. VI.

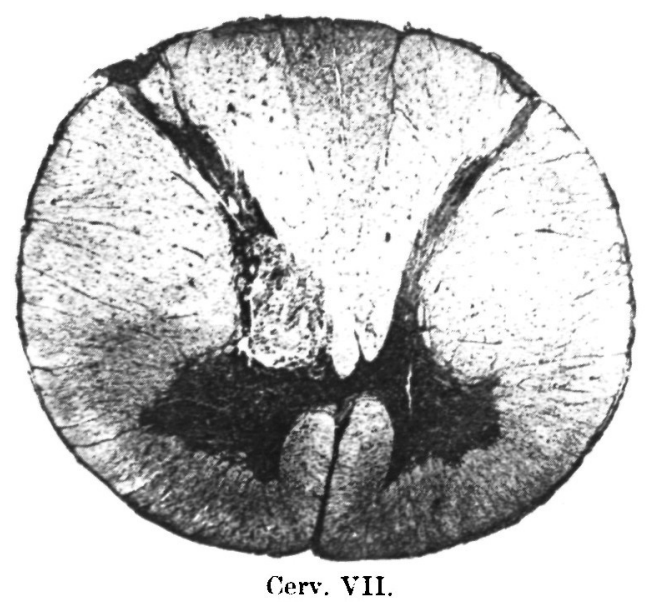

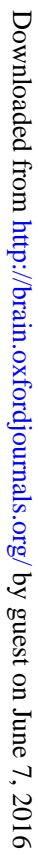


puate il.

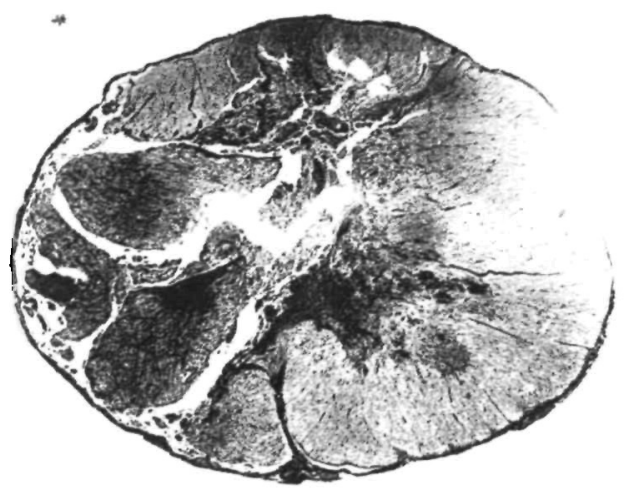

Cerv. VIII.

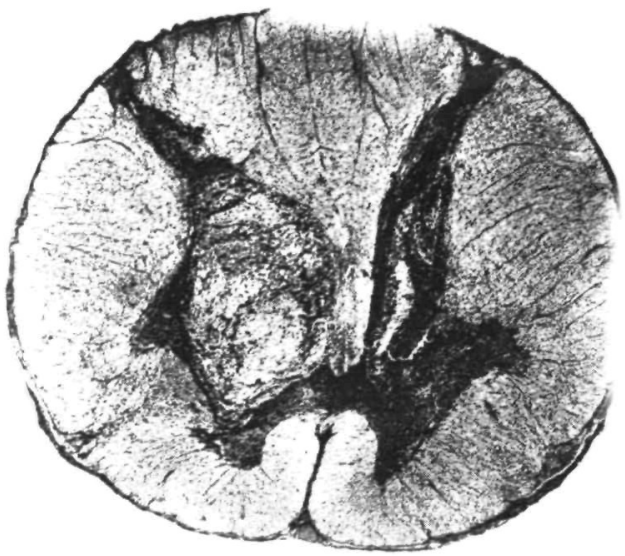

I)ors. 1 .

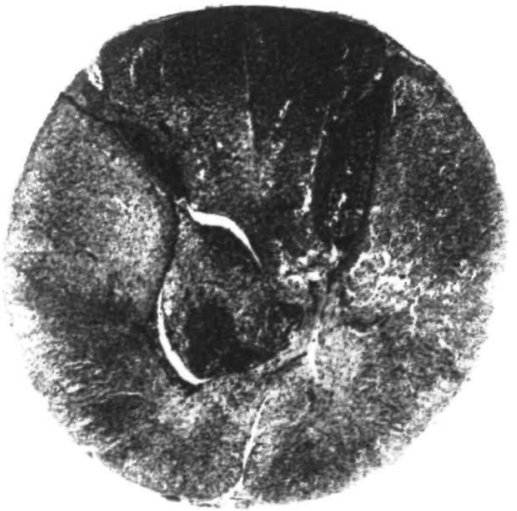

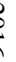

Dors, II. 
The pupils reacted slowly to light and in accommodation, but did not dilate when the neck was irritated. The lids were not as widely opened as they should have been. It was thought that the cilio-spinal centre had been affected.

His mind was clear up to the time of his death, which occurred about thirty-six hours after the injury; his condition remaining the same. An attempt was made to operate, but the change of position produced such disturbance of respiration that it was abandoned. The following account of the autopsy was kindly furnished me by the pathologist, Dr. John K. Thacher, and the appearance of the cord is shown in the plates made from photographs of sections prepared by Dr. Power. (Plates I. and II.)

On dissection of the vertebral column, the laminæ of the sixth cervical vertebra were found fractured, and there was a dislocation forward of the vertebral column between the fifth and sixth spinous processes, and between the bodies of the sixth and seventh vertebræ. At this point the cord was compressed and softened. Microscopical examination showed much crushing and hæmorrhage. The whole of the left half of the eighth segment was broken up, as well as the right posterior column except its posterior edge. The fibres and cells were destroyed, and there were many hæmorrhages, especially in the gray matter. The gray matter of the right side was broken up, especially at the anterior part of the posterior horn and showed some extravasation of blood. But the tip of the posterior horn and some of the anterior portions of the anterior horn appeared uninjured, as did also the anterior and lateral colnmns of white matter.

Passing upwards from the segment crushed, to the seventh segment, a spot of disintegration and hæmorrhage was found involving the anterior half of the left posterior horn and a little of the adjacent anterior horn and lateral and posterior white column. The hæmorrhage also extended in a narrow line along the outer edge of the posterior horn nearly to the surface of the cord.

In the sixth segment the same appearances were found, but in the fifth the tissues were normal.

vOL. XVII. 
Passing downwards to the dorsal region of the cord, in the first dorsal segment a displaced mass of white matter was noticed replacing most of the gray matter of the left side and surrounded by a zone of hæmorrhage. On the right side there were numerous hæmorrhages scattered through the gray matter, and apparently a small displaced mass of white matter in the base of the posterior horn.

In the second dorsal segment the lesion on the left side was similar to that in the previous segments, but a little smaller. On the right side no hæmorrhages were seen in the anterior horn, but in the posterior horn was a long narrow oval hamorrhage running nearly the entire length of the horn.

In the third dorsal segment no lesion was to be seen on the left side, but in the right posterior horn the same hæmorrhage found in the preceding segment was again found, though smaller.

Below the third dorsal segment the cord appeared to be normal.

Summary.-The lesion, therefore, consisted of a disintegration of the cord at the eighth cervical segment and a hømorrhage in the two segments above and below this, especially on the left side of the cord.

In regard to the area of anæsthesia upon the body it is to be noticed that it was much below the level of the.lesion. Sensations were felt in slight degree above the level of the seventh rib; they were fairly well felt above the nipples, they were quite normally felt above the third rib. This preservation of sensation upon the body at a level some distance below the lesion, is not unusual. I have careful records of several cases of transverse myelitis in the dorsal region with antopsies in which this condition has been noticed. And the cases reported by Church and Eisendrath ${ }^{2}$ may be cited in confirmation of the fact. It is noticed that, except on the ulnar side of the forearms and arms and in the hands, the anæsthesia in my case was not total. The hands were both totally anæsthetic. 
Case VIII. - Caries of cervical vertebra. BrownSéquard paralysis. Death.

A girl of 15, previously in good health, noticed in August that her neck was becoming stiff and painful on motion. The pain was in the course of the great occipital nerves, and by October her head had become so rigid that no active or passive motion of the neck was possible. During October weakness in the arms, especially in the left arm, began, and soon the left leg also became weak. She was sent to my clinic on October 22, and then presented the following symptoins. The head was held rigid, turned slightly to the right, the chin slightly elevated, and passive motion was prevented by the rigidity of the deep muscles of the neck as well as by a deformity of the spine, which was evident both by a deep hollow in the neck at the fourth and fifth cervical vertebrø and by a projection at the back of the pharynx. Pain in the neck and over the back of the head was a prominent symptom, but was not associated with anæsthesia. The left upper extremity was partially paralysed, all movements being very much impaired; those at the shoulder and elbow joints more than those at the wrist and fingers. No motion of the arm was possible, it hanging helpless. Motions of the forearm were very weak, extension being impossible; the forearm was semiflexed upon the arm. While all the fingers could be moved, she had no grip. The triceps and wrist tendon reflexes were greatly exaggerated, a triceps clonus being obtained. All sensations were perceived equally in the left side and in the face; and the muscular sense was keen and quick.

The left lower extremity was weak, both at hip, knee, and ankle joints, and the tendon reflexes were much exaggerated. The sensation was normal ; that is, the same as in the face.

The right apper extremity was freely moved, but was markedly anøsthetic up to the shoulder. Tactile sensations, sensations of pain, heat, and cold were not perceived by any means as promptly, as accurately, or as intensely as in the corresponding part of the opposite limb. There was marked 
ataxia of movement in the right hand when her eyes were closed : and the perception of its position was less rupid and accurate than on the left side. There was no motor paralysis and no increase of tendon reflexes.

The right lower extremity was not paralysed, the kneejerk was normal, no ankle clonus was obtained. The same kinds of anæsthesia were found as on the right arms, though sensations were rather better in the lower than in the upper extremity. The area of anæsthesia is shown in fig. 11.

The gait was much impaired. She staggered in standing and walking, with a tendency to fall toward the right when her eyes were closed, and her gait was decidedly ataxic.
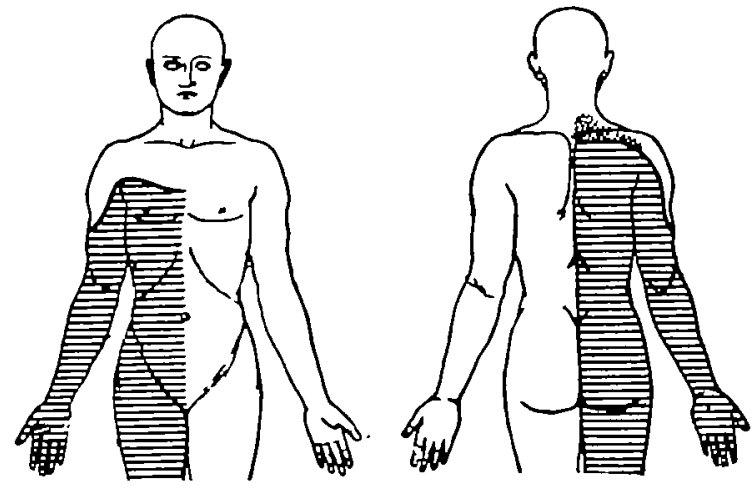

Fio. 11.

Case VIII.-Starr. Anæsthesia in lesion of fifth cervical segment.

The control of the sphincters was somewhat impaired. She had to wait a long time before her water would pass, and a loss of voluntary control of the bladder soon ensued, so that a catheter had to be used.

There was no hyperæsthesia of the paralysed side and no bend of anæsthesia about the trunk on that side.

By the end of November, all of the symptoms had increased in intensity, the paralysis of motion of the left side being complete, and the anæstbesia on the right side being increased; she was unable to sit up or to control her sphincters. She bad distressing attacks of dyspnoea. 
The condition finally became one of total paraplegia, and in January she died.

Diagnosis.-It was evident from the first that a caries of the fourth and fifth cervical vertebrø had resulted in a displacement of these bones, which had produced pressure upon the left half of the spinal cord at the level of the fifth and sixth cervical segments. That these segments or their nerves were seriously implicated was evident from the fact that a marked atrophy, as well as paralysis and a reaction of degeneration, was found to exist in the deltoid, biceps, triceps, supinator longus, supric and infra spinatus, and pectoral muscles of the left arn, while no such atrophy or reaction was found in the other muscles in spite of their paralysis. In the right arm the anæsthesia was more marked over the back of the shoulder and arm and on the outer side of the arm and forearm than elsewhere. The pressure was sufficient to cut off, to some extent, motor impulses downward to the left leg on the side diseased, and sensory impressions of all kinds from the right side of the body below the level of the lesion.

Operative interference appeared to be impossible, and the disease made rapid progress, producing finally total paraplegis and death from respiratory paralysis. An autopsy wos not made.

With the cases already cited it would easily be possible to lay down certain districts of skin upon the upper extremity, and assign each district to its segment of the cervical cord. It would be possible to cite also numerous cases of stab wounds of the cord and of tumours of the cord which confirm these conclusions.' But did we attempt this the objection might reasonably be raised that from traumatic cases where shock cannot be excluded and where temporary effects cannot be wholly distinguished from permanent effects such conclusions would be unwarranted.

The following case, however, is not open to this objection, and appears to afford exactly such information as is needed to enable an exact localisation to be reached.

' Inoised wounds of the spinal cord. Neumann, Virchow's Arch., craii. h. 9. Sach8, Jour. Nerv. and. Ment. Dis., xiii., November, 1886. 
It is a case of sarcoma growing upon and invading the cord upon one side, beginning at the lower cervical and first dorsal segments, and extending gradually to other segments. As the sarcoma grew the anæsthesia increased in extent.

Case IX.-Tumour of the lower cervical region of the cord with progressive ancesthesia. ${ }^{1}$

Male, 29, began to suffer in May, 1891, from numbness in the ulnar side of the right little finger. The numbness, which was attended by actual anæsthesia, gradaally extended to the entire little finger, then to the ring finger and then to the ulnar side of the middle finger. As it extended to the ring and middle fingers it extended to the ulnar surfaces of the hand, and then gradually up the ulnar surfaces of the forearm and arm, to the axilla which were anæsthetic in August, 1891. Later, the anæsthesia increased upon the band, gradually reaching the thumb, and then including it; and finally advanced up the radial border of the forearm and arm to the insertion of the deltoid, at which point it ceased about thirteen months after the onset. Parallel with this extension of sensory loss there was a gradual extension of paralysis with atrophy and reaction of degeneration. The paralysis began in the interossei and hypothenar eminence, then invaded the thenar eminence, then the long flexors of the fingers, and then all the muscles of the forearm except the supinator. The muscles became rigid before they were paralysed, but relaxed again as degeneration set in. In the course of the year all the muscles of the arm became involved and paralysed except the supinator longus and the deltoid; the pectoralis major and shoulder muscles became rigid. From the first it was noticed that the right palpebral fissure was small, that the right lid drooped and that the right pupil was small.

In September, 1892, the patient died, a large sarcoma having developed in the chest.

1 Hoss and Herter, New York Medical Record, August 12, 1898. It is interesting to note that though the tumour was confined to one side of the cord the symptoms were not those of Brown-Sequard paralysis. The same fact vas noted in a case of spinal cord tumour seen by me with Sachs, and fully reported by him. 
The autopsy showed a small sarcoma lying upon and invading the spinal cord on the right side, extending up as high as the fifth cervical segment and as low as the third dorsal segment, but being largest at the lowest cervical and first dorsal level.

A somewhat similar case has been recently reported by Murray and Johnson, ${ }^{1}$ and several others might be cited of either tumour or myelitis advancing up the cervical cord and producing a gradual extension, both of paralysis and of anæsthesia. As the symptoms, however, in all these cases are identical, it does not seem worth while to cite them in full.

There are certann other facts which may be mentioned as affording confirmatory evidence of the areas of skin corresponding to the segments of the cervical enlargement. It is well-known to everyone who has watched the progress of cases of locomotor ataxia of the ordinary progressive type that as the disease ascends the cord the numbness and pain begin in the upper extremity in the little finger, then extend to the ring finger and then up the inner border of the hand and forearm. Finally the entire hand becomes numb and the thumb is the last to be ataxic. Thus the extension of the sensory symptoms in this disease corresponds quite exactly with that which has just been described in the case of cervical tumour.

There is also a disease which quite commonly invades the upper part of the cervical cord, viz.: chronic hypertrophic pachymeningitis. It is to be remembered that in this disease the pain is felt chiefly in the neck over the tops of the shoulders and in the outer side of the arms, and only rarely in the forearms and hands. The characteristic position of the hand and wrist pictured by Charcot' is explained by him as due to contracture of the muscles irritated by invasion of the nerves from above downward, the radial and median being affected, the ulnar escaping. Thus we see the exact converse of the picture presented by the advance of the disesse locomotor ataxia.

' Medico-Chirurgical Transactions, vol. Lov., p. 47, 1892.

"Leçons sur les Mal. du Syst. Nerv., vol. ii., p. 251. 


\section{CONCLUSIONS.}

There are a number of interesting facts to be drawn from the study of the cases here collected.

First, as to the distribution of anæsthesia in lesions of the cervical enlargement of the spinal cord. By combining the diagrams already given with numerous other diagrams
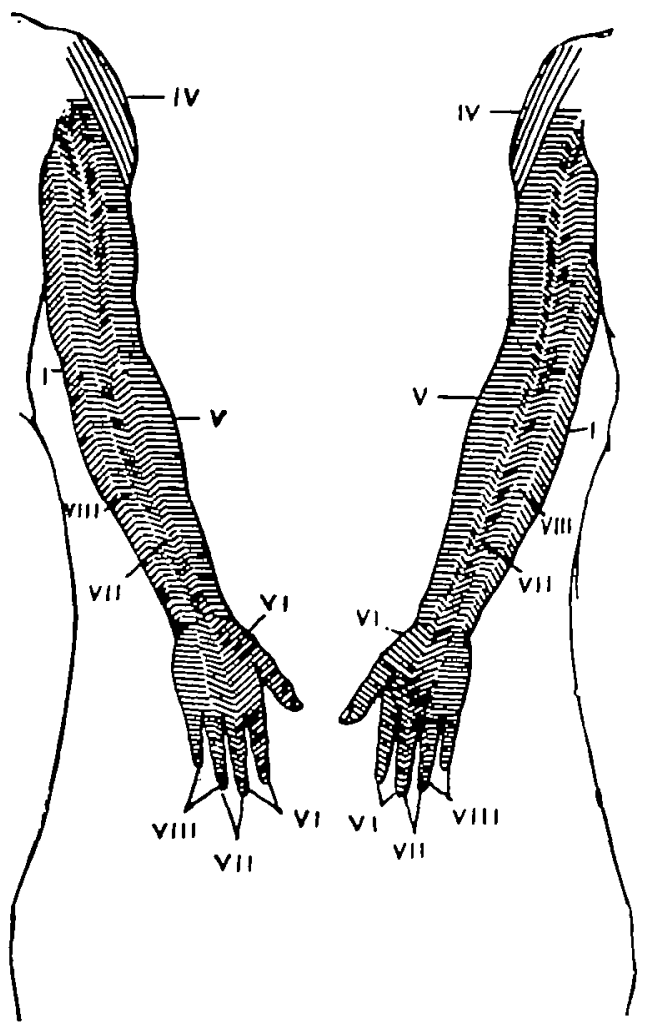

FIG. 12.

Diagram to show the area of skin upon the upper extremity related to the different segments of the spinal cord from first dorsal to fourth cervical.

published by Thorburn and others, and comparing the results with descriptions of numerous cases collected by Chipault, White and other surgeons, it is possible to produce a schematic diagram such as is here presented demon- 
strating the areas of skin upon the arm which are related to the various segments of the cord between the second dorsal and the fourth cervical. (Fig. 12.)

(1) The first area is a narrow one upon the inner side of the arm and forearm extending down to the wrist but not involving the hand. 'This includes a small zone both upon the dorsal and palmar surfaces of the arm and forearm, but is quite narrow. While it is probable that the upper portion of this area in the axilla is related to the second dorsal nerve, as Head maintains, I can find no exact lesion of the cord limited to the second dorsal segment and associated with such a limited anæsthesia to prove this statement.

There is a case reported by Charcot $^{1}$ in which a bullet wound involved the first dorsal nerve only, and in which a small area in the axilla remained sensitive; the other parts included in area number one being anæsthetic, but as no examination of the cord was made in this case the conclusion drawn from it is of no more weight than that which might be drawn from a knowledge of the anatomy of the intercostal humeral nerve. Area number one corresponds to the first dorsal segment.

(2) The second area includes the ulnar side of the hand, both palmar and dorsal surfaces, the little finger and one half of the ring finger. It also includes a narrow strip of the skin upon the dorsal and palmar surfaces of the arm up to the axilla. This is proved by the fact that when lesions invade the eighth cervical segment of the cord the zone of anæsthesia upon the front and back of the arm and forearm is decidedly wider than when the first area alone is anæsthetic. It affords also a confirmation of the statements of Sherrington that there are no isolated patches of skin entirely separated from the body related to the sensory nerves. The second zone corresponds to the eighth cervical segment.

(3) The third zone extends to the middle line of the middle finger, includes the middle of the palm and back of the hand, and runs up the centre of the forearm and arm on both surfaces. This corresponds to the seventh cervical segment.

\footnotetext{
'Arch. de Neurol., 1891.
} 
(4) The fourth zune includes the remaining skin of the fingers and thumb and of the hand as high as the wrist and a narrow strip of skin up the forearm and arm on both surfaces to the axilla. This corresponds to the sixth cervical segment.

(5) The fifth zone includes tbe skin upon the outer side of the forearm and arm on both surfaces as high as the insertion of the deltoid muscle. This corresponds to the fifth cervical segment.

(6) The fact that in lesions as high as the fifth segment hyperæsthesia occasionally occurs over the top of the shoulder and in the region of the supra-clavicular nerves, leads us to believe that the fourth cervical segment is in relation with this area. But inasmuch as lesions of the fourth segment of a destructive nature are uniformly fatal no case of anæsthesia can be found to determine the exact extent of skin which corresponds respectively to the fourth and third cervical segments.

It is hardly necessary to point out the differences between the areas of anæsthesia produced by cord lesions and those produced by lesions of individual nerve trunks, although a glance at the diagram and its comparison with Flower's well-known plates show this immediately. It is also evident that a contrast of the anæsthesia occurring in spinal cord lesions with that occurring in multiple neuritis affords an important point of diagnosis between these two conditions. It will be remembered that in multiple neuritis, the anæsthesia affects all the fingers simultaneously, then the entire hand, and then extends up the arm, involving all surfaces on both sides in an area which has been aptly described as the "glove area" corresponding as it does to the region of skin covered by a glove of various lengths. I have never seen a case of multiple neuritis in which the anæsthesia extended as high as into the axilla. It is usually limited by a line drawn around the elbow or a line in the middle of the arm.

Lastly, the area of anæsthesia occurring in hysterical conditions is different from that described as occurring in spinal lesions, for there is never the patch of normal 
sensitive skin over the top of the shoulder and down the outer side of the arm to the insertion of the deltoid such as we have seen in all the cases of spinal lesions; and in hysterical anæsthesia it is well known that the neck is usually anæsthetic.

Clinical observers in the future should attempt by the aid of diagrams to define a little more exactly the region of the anæsthesia in the arm and should also seek for a narrow zone of hyperæsthesia separating the normal skin from the insensitive region, which zone will necessarily be very narrow in the upper extremity. In discussing the anæsthesia from lumbar lesions, I was able to show that such a zone of hyperæsthesia often existed of a most irregular shape in unexpected areas which were easily explained when the exact region of the skin, corresponding to the segment just above the lesion was determined. ${ }^{1}$

Secondly, lesions in the lower cervical region of the cord produce a number of symptoms due to a lesion of the ciliospinal centre which have been frequently overlooked by observers. The situation of this centre is in the first dorsal segment of the cord, and according to Klumpe, ${ }^{2}$ the symptoms are only produced by a lesion of the cord, or of its nerve roots, not by a lesion of the nerves after they bave issued from the spinal canal and formed the brachial plexus.

The symptoms alluded to are myosis, with sluggish reaction of the pupil both to light and in accommodation, a decided narrowing of the palpebral fissure, so that the eye-ball looks smaller than normal, and a slight retraction of the eye-ball. There is no flattening of the face, nor are there any vaso-motor symptoms such as may be produced by a lesion in the course of the cervical sympathetic nerve. These symptoms are very easily overlooked if they are present apon both sides. But when the lesion has been unilateral they have been noted by a number of observers.

Kraus $^{8}$ has described them in a number of cases of tran-

${ }^{1}$ L.c., see Coses V. IX. and XII.

'Klumpe, Rev. de Med., 1885, No. 7 and 9.

'Kraus, Zeitsch. filr Klin. Med., vol. xviii. 
matic injury of the cervical cord due to fracture of the seventh cervical vertebra.

In a case of unilateral compression of the cord by a fracture of the seventh cervical vertebra which I recently saw with Dr. Bryant, at St. Vincent's Hospital, these symptoms were very noticeable upon the left side. I believe with Kraus that a more careful observation will reveal the existence of these symptoms on both sides in all cases of a crush of the lower part of the cervical and upper dorsal region.

Thirdly, a careful study of the cases here collected furnishes additional evidence in regard to the localisation of the motor functions of the spinal cord. This serves to confirm very fully statements made by me in $1884,{ }^{1}$ and again in $1888,{ }^{2}$ in regard to the representation of the varions muscles of the upper extremities in different segments of the cervical region.

In the articles alluded to, it will be found that every muscle is assigned a representation in more than one segment of the cord, and this fact has been accepted by Mills $^{3}$ and by Kaiser. ${ }^{4}$ It is well-known that the groups of cells in the anterior horns of the cord have a considerable extent vertically, so that some groups are long enough to reach through two or even three segments and bat very few groups can be said to be situated in one segment only. But inasmuch as these groups of cells govern individual muscles, as we must believe in view of the facts known regarding anterior poliomyelitis, it is evidently a mistake to assign the representation of single muscles to single segments. I cannot therefore adopt the arrangement proposed by Thorburn ${ }^{b}$ and copied by Collins, ${ }^{\circ}$ in which individual muscles are assigned to single segments.

If cases such as these here collected are carefully studied it will be found that a lesion limited to one segment rarely paralyses any muscle completely. If, however, the lesion

' Amer. Jour. of Neurology, Angust, 1884.

= Amer. Joutr. Med. Sci., May, 1888.

'C. K. Mills, Mherapertic Gasette, May and June, 1889.

'O. Kaiser, Die Functionen der Ganglienzellen des Halsmarks, Hasg, 1891 .

$\triangle$ Loc. cit.

- New York Medical Journal, February, 1894. 
extends through two or more segments the paralysis is complete. Or, if a lesion is a progressive one extending either upward or downward, it will be found that the muscles will be paralysed in greater and greater degree as the lesion extends. These facts are only to be explained upon the theory that individual muscles have a considerable vertical representation in the cord, and this as we bave already seen corresponds to the anatomy of the groups of cells. The following table, therefore, presents the facts in an accurate manner.

I am quite prepared to admit that the vertical extent of individual groups of cells may rary in different individuals. Thus in cases carefully studied by Beevor and by Johnson, the lesion, though involving the sixth cervical segment, caused no paralysis of the biceps; while on the other hand, in one of Herter's cases the biceps was decidedly involved by a lesion of the sixth segment. It is, therefore, probable that the representation of muscles is not always the same in different cords. The table, however, may be considered as fairly accurate because it combines a large number of facts derived from the study of very many cases. It is, perhaps, more accurate than the earlier tables. In recent cases care has been taken to examine the paralysed muscles electrically, and the existence of the reaction of the degeneration is certainly a positive proof that the groups of cells governing the muscles have been destroyed.

In conclusion, I think it may be stated that the sensory and motor fanctions of the cervical region are now as well determined as those of the lumbo-sacral region of the spinal cord.

The plates show the disintegration of the spinal cord at the eighth cervical segment, and the hæmorrhage into the cord in the segments above and below it in Case VII. 


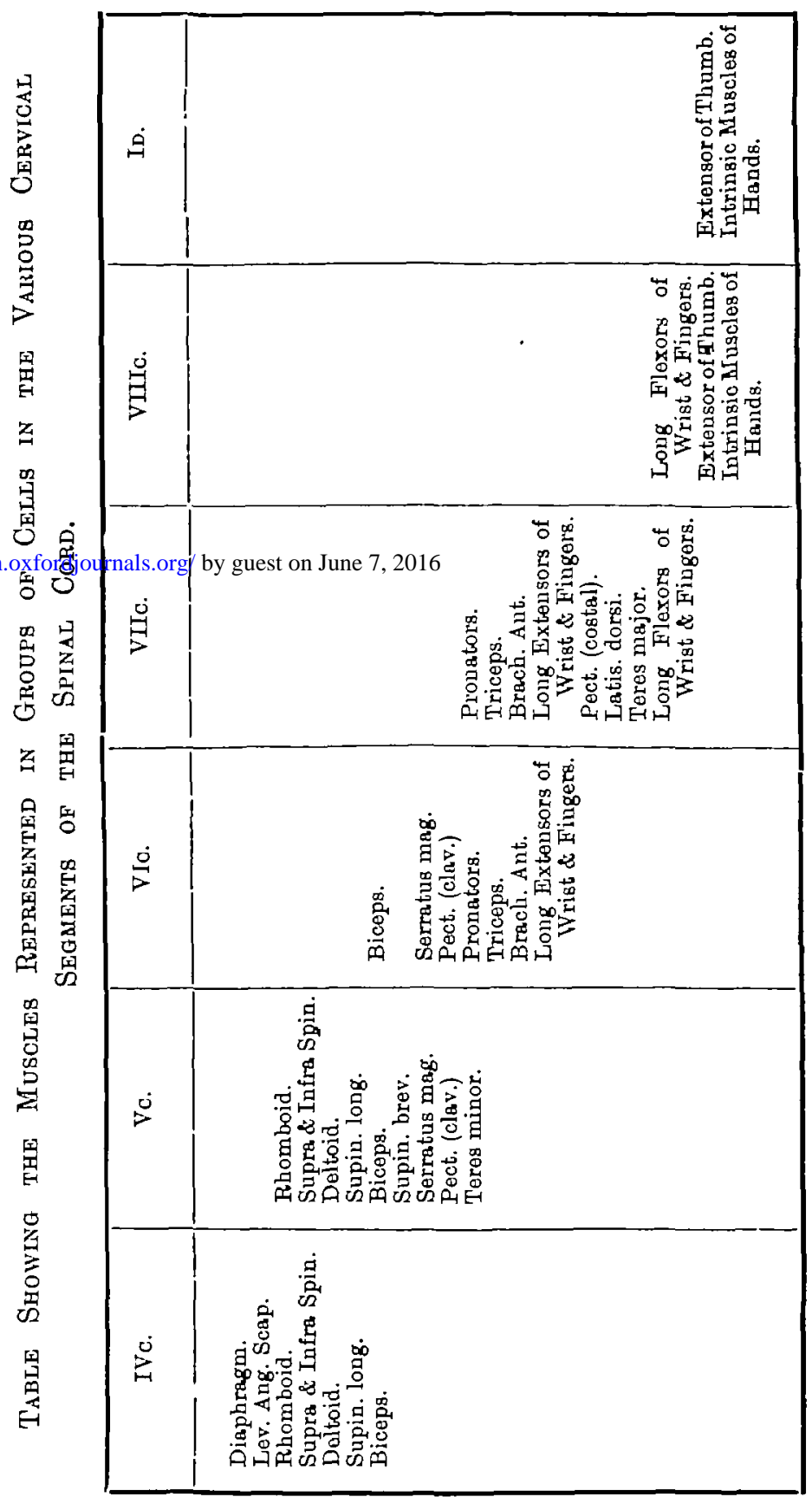

